University of Wollongong

Research Online

Faculty of Social Sciences - Papers (Archive) Faculty of Arts, Social Sciences \& Humanities

2013

Measuring optimism in organizations: development of a workplace explanatory style questionnaire

\author{
Paul Smith \\ University of Wollongong, paulsm@uow.edu.au \\ Peter Caputi \\ University of Wollongong, pcaputi@uow.edu.au \\ Nadia Crittenden \\ University of Wollongong, nadiac@uow.edu.au
}

Follow this and additional works at: https://ro.uow.edu.au/sspapers

Part of the Education Commons, and the Social and Behavioral Sciences Commons

Research Online is the open access institutional repository for the University of Wollongong. For further information contact the UOW Library: research-pubs@uow.edu.au 


\title{
Measuring optimism in organizations: development of a workplace explanatory style questionnaire
}

\begin{abstract}
Some researchers measure optimism by analysing explanations for hypotheti- cal scenarios in explanatory style questionnaires. The most commonly used instrument, the Attributional Style Questionnaire (ASQ), has been shown to predict success in business, education and sport. However, these predictions were achieved by using composite scores of subscales. Our analysis of 15 measures revealed the ASQ and many other explanatory style questionnaires have low internal consistency. Furthermore, the majority of these measures use situations that have poor face validity for corporate applications, while some work-specific scenarios are only relevant to narrow domains such as selling insurance. To fulfil the need for a work-related explanatory style measure that could assess levels of optimism in any organizational setting, we developed the Workplace Explanations Survey (WES). This 5 -factor measure was tested on a sample of 341 individuals working in a range of organizations and it has good internal consistency. We anticipate the WES will stimulate research into workplace optimism and provide clearer insights for optimism training, thus boosting both individual and organizational success.
\end{abstract}

\section{Keywords}

development, workplace, explanatory, measuring, optimism, style, organizations, questionnaire

\section{Disciplines}

Education | Social and Behavioral Sciences

\section{Publication Details}

Smith, P. A., Caputi, P. \& Crittenden, N. (2013). Measuring optimism in organizations: development of a workplace explanatory style questionnaire. Journal of Happiness Studies, 14 (2), 415-432. 


\title{
Measuring optimism in organizations: Development of a workplace explanatory style questionnaire
}

\begin{abstract}
Some researchers measure optimism by analysing explanations for hypothetical scenarios in explanatory style questionnaires. The most commonly used instrument, the Attributional Style Questionnaire (ASQ), has been shown to predict success in business, education and sport. However, these predictions were achieved by using composite scores of subscales. Our analysis of 15 measures revealed the ASQ and many other explanatory style questionnaires have low internal consistency. Furthermore, the majority of these measures use situations that have poor face validity for corporate applications, while some workspecific scenarios are only relevant to narrow domains such as selling insurance. To fulfil the need for a work-related explanatory style measure that could assess levels of optimism in any organizational setting, we developed the Workplace Explanations Survey (WES). This 5factor measure was tested on a sample of 341 individuals working in a range of organizations and it has good internal consistency. We anticipate the WES will stimulate research into workplace optimism and provide clearer insights for optimism training, thus boosting both individual and organizational success.
\end{abstract}

Keywords Explanatory style measures - Optimism - Workplace events - Organizations Success

\section{Introduction}

Seligman (1991, 2006, 2011) has popularized the role of optimism/pessimism in predicting depression, posttraumatic stress disorder (PTSD) and physical health, as well as achieving success in business, education, sport and politics. However, he describes a markedly different way of looking at optimism compared to the everyday view that links optimism to expectations of future events (Carver et al. 2009). Seligman and other researchers measure optimism by analysing explanations for hypothetical scenarios (Peterson and Steen 2009). This approach has led to hundreds of studies of explanatory style, the habitual, long-term way we explain why things happen (Dykema et al. 1996). Diverse collections of hypothetical events have been used to construct many different measures called explanatory (or attributional) style questionnaires. Peterson and Seligman (1984) recommend 'explanatory style' as a replacement for attributional style even though their primary research instrument is the Attributional Style Questionnaire (ASQ; Peterson et al. 1982). We support this name change as 'explanation' is more likely to be used and understood by a layperson than 'attribution'. The terms explanatory style and attributional style are now used interchangeably in empirical research (Ciarrochi et al. 2007; Dykema et al. 1996; Hewitt et al. 2004).

It should be noted that explanatory style is also measured by assessing explanations for reallife situations. This involves a technique called Content Analysis of Verbatim Explanations (CAVE) which was developed by Peterson, Luborsky and Seligman (1983). CAVE has been used in diverse research, including the investigation of the role of explanatory style in politics (Zullow et al. 1988), stability of explanatory style over 52 years (Burns and Seligman 1989) and predicting physical health over a 30 year period (Peterson et al. 1988). However, the CAVE technique is used in relatively few studies, possibly because it is more time 
consuming than using explanatory style questionnaires as it requires the training of judges to independently rate explanations over three dimensions. Therefore, it was not surprising to find only one study that used CAVE to investigate the relationship of explanatory style with occupational and organizational success (Henry, 2005).

An explanatory style is a tendency to explain events in a particular manner. It is most commonly based on three dimensions: internality (level of personal responsibility), stability (temporary versus long-lasting causes) and globality (specific versus generalized causes) (Peterson and Chang 2003). An example of a global explanation for a drop in productivity in a company would be "There is no communication from managers." A specific, much less generalized explanation is "One manager acts like a bully." An explanation containing a stable cause is: "Staff are never interested in any new training." Alternatively, a temporary, less stable explanation would be "The last couple of training sessions were poor." Seligman and his colleagues argue that an optimistic person is someone with an optimistic explanatory style which in turn means they tend to rely on external, temporary and specific causes when explaining problems, setbacks and failures. Alternatively, a person who is likely to explain successes and other positive events with internal, long-lasting and generalized causes is also said to have an optimistic explanatory style (Peterson and Steen 2009; Seligman 1991; Seligman et al. 1995). Therefore, explanatory style theory defines a pessimist as someone who prefers to explain negative situations with internal, stable and generalized causes or explains good events with external, temporary and specific causes (Seligman 1991).

Seligman $(1991,2011)$ posits that an optimistic explanatory style increases chances of success in many areas because it leads to greater determination and resilience. Studies have shown that an optimistic explanatory style leads to success in areas such as sales performance (Corr and Gray 1995; Corr and Gray 1996a; Seligman and Schulman 1986), education (Peterson and Barrett, 1987) and sport (Gordon, 2008; Martin-Krumm et al. 2003; Seligman et al. 1990; Sellers and Peterson 1993). In all of these studies, it was necessary to combine scores from the individual dimensions to achieve satisfactory criterion validity. This process creates composite scores, one each for negative and positive events, respectively called CoNeg and CoPos, as well as a total score called CPCN which is calculated by subtracting CoNeg from CoPos. There is a widespread practice among explanatory style researchers to bolster alpha coefficients to acceptable levels by combining scores from subscales.

Unfortunately, very few empirical studies over the last decade have explored the relationship between explanatory style and success in organizations. In addition, Martinko et al. (2006) state in their review of attribution theory that it is surprising that little has been done to implement the principles of explanatory style theory into organizational training. Only a few studies have been reported that used training to develop optimistic explanatory styles. However, these interventions have achieved major success with diverse groups, including insurance salespeople (Proudfoot et al. 2009), long-term unemployed (Proudfoot et al. 1997) schoolchildren and their teachers in suburban and inner-city schools, ranging from Philadelphia to Beijing (Seligman et al. 1995; Seligman 2011). In Australia, the Geelong Grammar School recently trained 160 teachers at the school to help develop optimism among the students and staff (Norrish and Vella-Brodrick 2009; White, 2009). Finally, the US Army is presently implementing a resilience training program involving 900,000 soldiers that aims to develop optimistic explanatory styles. This program was initiated to help reduce levels of depression and PTSD in military personnel (Seligman 2011). 
The present paper will proceed in the following manner. First, we undertake an in-depth review of 15 explanatory style questionnaires. Our aim is to clarify the often contradictory theoretical and structural aspects of these measures. We then highlight persistent psychometric concerns, that is, many measures have poor internal reliabilities (Furnham et al. 1994). Further, we consider how relevant the hypothetical scenarios are for workers in various organizations. Taken together, the review will help explain why we support a plea made two decades ago by Peterson (1991a) that criticisms of explanatory style measures should not stifle interest in this valuable construct. We concur with Peterson and indeed, we posit the opposite is much more preferable. The development of new explanatory style scales with strong psychometric and theoretical foundations is likely to facilitate optimism research. This could lead to more interventions, especially optimism training in corporate settings. Therefore, in the final part of this paper we describe the development of a new explanatory style instrument called the Workplace Explanations Survey. It is designed to measure optimism in any organizational setting, including corporate, educational, medical, sporting and military.

\subsection{Evolution and variation of explanatory style measures}

In this section we review the diversity of formats and evolution of explanatory style measures. Developed in 1982, the ASQ is still the most commonly used measure of explanatory style (Peterson and Steen 2009). It measures optimism by providing six negative and six positive hypothetical scenarios, and asks the participant to write a single cause for each event. The respondent then rates each cause along the three dimensions of internality, stability and globality on 7-point scales. Thus, the ASQ consists of 36 items as none of the 12 written causes are analysed by the researcher (Peterson et al. 1982). The initial motivation for the development of measures based on the ASQ was primarily psychometric. In response to criticisms of low internal consistencies of the six sub-scales of the ASQ, the Expanded Attributional Style Questionnaire was developed (EASQ; Peterson and Villanova 1988). Peterson observed that "impetus for creating the EASQ lies in the unsatisfactory reliabilities of the original ASQ" (Peterson 1991c p. 180). The EASQ maintained the format of the ASQ except it was lengthened to include 24 negative events, six of which came from the ASQ. All positive events were omitted. This resulted in an improvement in the reliability with alpha coefficients for the individual dimensions being .66 for internality, .85 for stability and .88 for globality respectively (Peterson and Villanova 1988). Chang and Sanna (2007) used the EASQ to compare levels of pessimism in undergraduates and their parents. Notably, six events were dropped for the testing of the parents "given the questionable frequency or relevance to this population” (Chang and Sanna 2007 p. 1152).

Abramson and Metalsky developed the Cognitive Style Questionnaire (CSQ) in 1989 as an expanded and modified version of the ASQ, and it has been used in more than 30 published investigations (Haeffel et al. 2008). However, it was nearly two decades before a detailed report on its psychometric properties was published (Haeffel et al. 2008). Furthermore, Peterson, who was a member of the separate teams that developed the ASQ and the EASQ, also helped construct another explanatory style measure called the New Attributional Style Questionnaire (NASQ; Dykema et al. 1996) which assesses explanations for 12 negative events on only two dimensions: stability and globality. It appears the NASQ is rarely used in empirical studies. 
There is a popular untitled explanatory style questionnaire in Seligman's book, Learned Optimism (1991). It has a forced-choice format with 24 positive and 24 negative events. Readers are provided with instructions to allow self-assessment of optimism levels. Cheng and Furnham (2003) used this questionnaire to examine the relationship between explanatory style and self-esteem. They described the 48-item measure as another version of the ASQ, and consequently referred to it as the ASQ even though they note that no internal reliability is included in Seligman's book. However, Seligman stated that the instrument has been validated in many private studies carried out by American companies (personal communication, August 31, 1994). Cheng and Furnham (2003) provide the only known report on the internal reliability of this instrument. They found low Cronbach alphas for composite scores: $\mathrm{CoNeg}=.59$, CoPos $=.47, \mathrm{CPCN}=.57$ with no results for individual dimensions. Nevertheless, the first author of this article has encountered Australian training organizations that use this measure to provide optimism assessments of their corporate clients.

Cutrona et al. (1985) have challenged the cross-situational consistency of explanatory style. Instead, they recommend the assessment of explanatory style for specific domains. This proposal is supported by Ashforth and Fugate (2006) who state: "It is clear that a domainspecific measure of attributional style should more strongly predict certain outcomes than would a more generalized measure of attributional style” (p. 12). Researchers agreeing with this assumption have developed a wide range of domain specific attributional measures: the Academic Attributional Style Questionnaire (AASQ; Peterson and Barrett 1987), the Sport Attributional Style Scale (SASS; Hanrahan et al. 1989), the Children's Attributional Style Questionnaire (CASQ; Seligman et al. 1984) and the Children's Attributional Style Questionnaire-Revised (CASQ-R; Thompson et al. 1998).

Eight measures have been identified that assess explanatory styles specifically for work domains. These instruments are the Occupational Attributional Style Questionnaire (OASQa; Furnham et al. 1992), Occupational Attributional Style Questionnaire - Revised (OASQ-a Rev; Furnham et al. 1994), Organizational Attributional Style Questionnaire (OASQ-b; Kent and Martinko 1995), Organizational Attributional Style Questionnaire II (OASQ-b II; Douglas and Martinko 2001), Financial Services Attributional Style Questionnaire (FSASQ; Proudfoot et al. 2001), Work Attributional Style Questionnaire (WASQ; Ashforth and Fugate 2006), Leader Attributional Style Questionnaire (LASQ; Martinko et al. 2007) and Member Attributional Style Questionnaire (MASQ; Martinko et al. 2007). Table 1 shows a summary of the structural formats and internal reliabilities of the 15 explanatory style measures listed in this discussion.

The OASQ-a was "closely modelled on the ASQ in terms of its basic format, instruction and response scales” (Furnham et al. 1992 p.30). This description appears to be at odds with the structure of the OASQ-a which asks participants to rate their explanations over nine dimensions instead of the three found in the ASQ. The dimensions in the OASQ-a are internality, stability, probability, externality, chance, personal control, colleague control, forseeability and importance. Welbourne and her colleagues (2007) used the OASQ-a in a study of job satisfaction. The participants were 190 nurses and the study found positive occupational explanatory style associated with positive coping styles and greater career satisfaction (Welbourne et al. 2007). Proudfoot and her colleagues (2001) believed the 
reliabilities of the OASQ-a could be improved by expanding the number of hypothetical situations from 10 to 16. This lead to the development of the FSASQ (Proudfoot et al. 2001). However, most of the situations are not applicable outside the finance services sector.

Developed in 1995, the OASQ-b "applies specifically to attributions regarding negative organizational outcomes relating to areas such as pay, performance, evaluations and training opportunities” (Campbell and Martinko 1998 p. 182). It uses a seven-point Likert scale and the initial dimensions were controllability, stability, and intentionality. Externality was added to the revised format and the number of scenarios was reduced to eight (Douglas and Martinko 2001). The OASQ-b has been used in research on workplace aggression and revenge (Douglas and Martinko 2001). Chiu and Peng (2008) used a modified version of this scale in an investigation of employee deviance.

\subsection{Explanations for positive or negative events?}

The next component of our review of explanatory style measures focuses on a dichotomy of definitions of explanatory style. Some researchers take the broader view that includes explanations for both positive and negative events (e.g., Martin-Krumm et al. 2005). This approach allows a person to have three possible explanatory styles, one each for good and bad scenarios, or a single composite of both. Other researchers limit the definition to explanations of negative events (e.g., Dykema et al. 1996; Sanjuan and Magallares 2009). The situation is further complicated given that different approaches have been taken even by the same researchers. For instance, Seligman and Peterson have often restricted explanatory style to negative events (e.g., Jackson et al. 2002; Peterson and Barrett 1987; Peterson, 1991a; Peterson et al. 1988; Sellers and Peterson 1993) as well as extending the definition to include positive and negative events (e.g., Peterson and Steen 2009; Schulman et al. 1989; Seligman 1991).

The observed differences in what constitutes explanatory style might result from the question of whether explanations for positive and negative events are two sides of a single coin, or two separate coins. There is strong evidence to support the latter view as explanatory styles based on either good or bad events are often independent of each other (Peterson 1991a; Xenikou 2005). Therefore, Peterson (1991a, 1991b) argues against the use of a single explanatory style, that which results from combining the scores for explanations of negative events with explanations of positive events. He stated that a "composite cannot be justified until there is a theoretical reason that compels it" (Peterson 1991a p.4). His warning is frequently rejected by researchers who use a composite of bad and good events to measure explanatory style (e.g., Cheng and Furnham, 2003; Ciarrochi and Heaven 2008; Gordon 2008; Seligman 1991; Thompson et al. 1998). Sometimes, even Peterson includes the composite of positive and negative events in his research (Martin-Krumm et al. 2005).

Furnham and his colleagues (1992) found a significant relationship between explanations for positive work-related events (measured by the OASQ-a) and organizational status, salary, job satisfaction and motivation. This contradicted findings that showed explanations for negative situations, and not those for positive events, were predictors of success (Peterson and Barrett 1987; Seligman 1991; Seligman and Schulman 1986; Sellers and Peterson 1993). However, there are concerns as the OASQ-a was validated on a small sample of only 53 men and 37 women. In two predictive validity studies of the ASQ, Corr and Gray (1995; 1996a) found 
explanatory style based on explanations of positive events correlated with insurance sales performance, which was measured by prospects obtained and sales of policies. These studies with large British insurance companies did not support the findings in American insurance sales which showed explanations for negative events predicted performance (Seligman and Schulman 1986). In contrast, Xenikou et al. (1997) argue that explanatory style based on negative events has greater reliability and validity than measures of positive events. They cite Burns and Seligman (1989) who showed that explanatory style for negative situations was stable over a 52 year period of adult life, but there was no stability for explanations of positive events. No other longitudinal study could be found which investigated the stability of explanatory style over a period beyond a year. Typical of longitudinal studies is the 5-week test-retest correlation study done in the original validation of the ASQ with 100 undergraduates (Peterson et al. 1982).

Peterson (1991a) offers a range of reasons for relegating and even ignoring explanatory styles based on positive events. He suggests that people are less mindful when thinking about positive events less likely to provide deep thinking, and more likely to rely on clichés for positive situations. He recommends that further research is needed to discover why explanatory style for bad events is independent of that for good events. This suggestion appears to have been ignored. Peterson sums up the situation by stating that explanatory style based on negative situations has more robust correlates than a positive event explanatory style (Peterson and Steen 2009).

\subsection{Internal consistencies of explanatory style questionnaires}

In this section we examine the major psychometric concern about explanatory style questionnaires. The ASQ has often been criticised for the poor internal consistency of its dimensions (Carver \& Scheier 1991; Peterson 1991c; Proudfoot et al. 2001). In the original study describing the development of the ASQ, Peterson and his colleagues (1982) report the following Cronbach alphas for the three dimensions of explanations for negative scenarios: .50 (internality), .58 (stability) and .44 (globality). The respective alpha coefficients for positive scenarios were .46, .59, .69. Higgins and Hay (2003) also found low reliability coefficients for ASQ dimensions. In their optimism measurements of 218 university undergraduates, the Cronbach alphas for negative event dimensions were .42 (internality), .46 (stability) and .46 (globality). The respective alphas for negative event dimensions were .36, .52 and .62. The OASQ-a has also been accused of the same major shortcoming (Heaven 1994; Kent and Martinko 1995) and other measures of attributional style have low to moderate internal consistencies even when dimensions are combined to form composite scores. For example, the alpha coefficients in the CASQ-R were .53 for positive events and .45 for negative events. (Thompson et al. 1998).

The internal reliabilities of the 15 measures in this review can be seen in Table 1 . This shows that there are only four explanatory style questionnaires that have satisfactory internal consistency (reaching at least .70) for all individual dimensions. These are the EASQ, OASQb, NASQ, FSASQ. However, the EASQ contains only negative scenarios, many of which are only relevant to undergraduate students (Peterson and Villanova 1988). Also, the OASQ-b also contains only negative events and two of its three dimensions, controllability and intentionality, are not used by other explanatory style researchers. Similarly, the NASQ assesses negative scenarios, and only on stability and globality. As stated previously, the 
NASQ appears to be rarely used in research. Finally, the FSASQ, whilst it does assess positive and negative situations on three dimensions, is specifically designed for the financial services sector.

Table 1 Structural Formats and Internal Reliabilities of 15 Explanatory Style Questionnaires

\begin{tabular}{|c|c|c|c|}
\hline $\begin{array}{l}\text { Explanatory style } \\
\text { measure }\end{array}$ & $\begin{array}{l}\text { Dimensions } \\
\text { measured }\end{array}$ & $\begin{array}{l}\text { Reliabilities of } \\
\text { dimensions }\end{array}$ & $\begin{array}{l}\text { Situations for } \\
\text { explanations }\end{array}$ \\
\hline ASQ (1982) & Internality, stability, globality & .44 to .69 & 6 negatives/6 positives \\
\hline AASQ (1987) & Internality, stability, globality & $\begin{array}{l}.84 \text { (Composite of } \\
\text { Intern/Stab/Glob) }\end{array}$ & 12 negatives \\
\hline EASQ (1988) & Internality, stability, globality & .66 to .88 & 24 negatives \\
\hline CSQ (1989) & $\begin{array}{l}\text { Internality stability, globality, } \\
\text { consequences, self-worth }\end{array}$ & .83 to .91 (Composites) & $\begin{array}{l}12 \text { negatives } \& \\
12 \text { positives (fillers) }\end{array}$ \\
\hline EASQ-S (1991) & Internality, stability, globality & .52 to .87 & 12 negatives \\
\hline $\begin{array}{l}\text { Unnamed measure in } \\
\text { Learned optimism (1991) }\end{array}$ & Internality, stability, globality & .47 to .59 (Composites) & $\begin{array}{l}24 \text { negatives/24 positives } \\
\text { (48 forced-choice items) }\end{array}$ \\
\hline OASQ-a (1992) & $\begin{array}{l}\text { Internality, externality, } \\
\text { stability, probability, chance, } \\
\text { personal control, colleague } \\
\text { control, forseeability }\end{array}$ & .44 to .79 & 5 negatives $/ 5$ positives \\
\hline OASQ-a Rev (1994) & $\begin{array}{l}\text { Internality, externality, } \\
\text { stability, globality, } \\
\text { personal control }\end{array}$ & .50 to .64 & 8 negatives/8 positives \\
\hline OASQ-b (1995) & $\begin{array}{l}\text { Stability, controllability, } \\
\text { intentionality }\end{array}$ & .70 to .80 & 16 negatives \\
\hline OASQ-b II (2001) & $\begin{array}{l}\text { Externality, stability, } \\
\text { controllability, intentionality }\end{array}$ & .89 (Composite) & 8 negatives \\
\hline NASQ (1996) & Stability, globality & .74 to .81 & 12 negatives \\
\hline FSASQ (2001) & Internality, stability, globality & .76 to .88 & 8 negatives/8 positives \\
\hline WASQ (2006) & $\begin{array}{l}\text { Internality, stability, globality, } \\
\text { controllability }\end{array}$ & .48 to .74 & 6 negatives/6 positives \\
\hline LASQ (2007) & Internality, stability & .73 (Composite) & 9 negatives \\
\hline MASQ (2007) & Internality, stability & .78 (Composite) & 9 negatives \\
\hline
\end{tabular}

Criticisms have been made about the scarcity of the use of confirmatory factor analysis (CFA) to confirm the three dimensional structure in the ASQ (Hewitt et al. 2004). In a Dutch study, Arntz et al. (1985) found only weak evidence for ASQ dimensions after using confirmatory factor analysis. They also reported weak predictive and discriminant validity of the subscales. However, the findings of Arntz at al. were based on their study of Dutch adolescents (mean age of 14.9 years), not adults. Even though some questions were modified to be more suited to teenagers, the researchers ignored the fact that the ASQ was designed for adults (Peterson et al. 1982). The findings of Arntz et al. (1985) were contradicted by a large study carried out by Hewitt and her colleagues (2004). They carried out multi-trait CFA of only half of the ASQ. They selected the negative event explanations for a study with 2748 university students from England and New Zealand. Their CFA findings supported the threedimension structure (internality, stability, globality) of the ASQ for the negative event explanations (Hewitt et al., 2004). Corr and Gray (1996b) examined the factors in the ASQ and found internality loaded on a different factor to a factor combining stability and globality. 
Although the EASQ has better psychometric properties than the original ASQ, the ASQ continues to be the preferred measure (Peterson and Steen 2009). Peterson, a developer of the EASQ, admitted that the format was too long, taking up to 30 minutes to complete, and a considerable number of items are often not attempted (Dykema et al. 1996). Furthermore, 18 of the 24 scenarios in the questionnaire are most relevant to undergraduate lifestyles. Jackson et al. (2002) used the EASQ to determine the interrelationship between explanatory style, stress and physical illness in college students. Whitley (1991) constructed a shortened 12 negative event version of the EASQ (EASQ-S). In two separate studies he found the EASQ-S provided lower Cronbach alphas than those obtained from the EASQ, but much higher than those of the ASQ. The internal consistency reliabilities of the EASQ-S were .65 and .52 and (internality); .79 and .79 (stability), and .87 and .76 and (globality). Peterson (1991c) rejected the need for the EASQ-S, stating the short form was a step backwards as it had lower reliabilities than the EASQ.

Xenikou (2005) reported that results of research into the relationship between explanatory styles and job performance have been inconsistent. She used a modified version of the OASQ-a with eight scenarios to investigate the separate effects of explanations for positive and negative events, as well as their interaction. Xenikou (2005) rejects any relevance of the internality dimension which is assessed the ASQ and other explanatory style measures. She argues that internality is not relevant as it predicts self-esteem, not motivation, and bases her proposition on a revision of the reformulated theory of learned helplessness (Abramson et al. 1989) which played a major role in the development of explanatory style theory (Peterson and Steen 2009). Peterson and Steen also agree that the internality dimension "has more inconsistent correlates than stability or globality, it is less reliably assessed, and there are theoretical grounds for doubting its impact on expectations" (Peterson and Steen 2009 p. 316).

\subsection{Face validity of hypothetical scenarios}

In an early critique of the ASQ, Tennen and Herzberger (1985) point out that several of the hypothetical events in the measure are irrelevant to some groups of people and recommend using scenarios with much broader relevance to the general population. In this section we suggest a possible reason for the low internal consistency connected to explanatory style measures. An extensive number of situations included in various attributional style measures appear to have limited face validity. Three of the twelve situations in the ASQ deal with romantic and personal relationships and are likely to have little relevance to a broad range of the population. These are: "You go out on a date and it goes badly", "Your spouse (boyfriend/girlfriend) has been treating you more lovingly", "You meet a friend who compliments you on your appearance”.

Even though the EASQ contains twice the number of situations found in the ASQ, it has a much larger potential for low face validity. Six scenarios are taken from ASQ plus 18 that specifically describe college/university related situations (Peterson and Villanova 1988). The AASQ was deliberately designed for a narrow domain, but a rich source of psychological research, university undergraduates. It contains outcomes such as "You do not have high enough grades to switch to your desired major". Likewise, the CSQ has more limited ecological validity than the EASQ as it was developed to specifically test undergraduates 
(Haeffel et al. 2008). It covers scholastic areas such as college coursework and romantic relationships. When the situations listed in the ASQ are compared to the narrow range of those in the EASQ, AASQ and CSQ, it is easy to see why the ASQ is the most commonly used measure of attributional style (Peterson and Steen 2009).

The FSASQ was designed for the narrow domain of selling insurance and hence, has very little application to other occupations or the general population. Whilst the FSASQ contains sales performance scenarios, many of these are not applicable to many types of sales careers. For example, "You fail your licensing exam", "You recruit a team of consultants and they leave", "You have found a significant number of good prospective clients", "You earn more than $\$ 4000$ commission on one case”. The WASQ contains the following positive events and their negative counterparts: "You surpass your sales quota", "The performance of your subordinates has gotten steadily better", "You do not meet your sales quota", "The performance of your subordinates has gotten steadily worse". For reasons given, above these situations provide limited face validity, even though this instrument was designed for a broad range of work settings (Ashforth and Fugate 2006).

\subsection{Development of the Workplace Explanations Survey}

We now describe the development the Workplace Explanations Survey (WES), an explanatory style questionnaire that we designed for use in any organizational setting. Our present review provides a range of insights for the development of new explanatory style questionnaires. The review revealed that those measures containing only negative scenarios were much more likely to show satisfactory alpha coefficients. However we decided to incorporate both negative and positive events for two reasons. First, we agree with Haeffel et al. (2008) who recommend that it is necessary to include some positive events to reduce the likelihood of response set bias. Second, there are contradictory results regarding whether explanations of positive or negative events predict success in corporate settings. The development of the WES is an exploratory study and therefore, we included both negative and positive scenarios (see Table 2).

The WES contains 16 hypothetical scenarios, eight negative and eight positive. These were chosen from a group of 30 events that had been extensively trialled by the lead author in optimism training workshops over a 10 year period. The workshops were delivered to business, educational, sport, military and governmental organizations in Australia. The face validity of the 16 scenarios was supported by feedback from naval officers, nurses, schoolteachers and principals, professional sportspeople and their coaches, local government managers and staff, plus employees from mining, engineering, transport, banking and finance organizations. This indicates the 16 scenarios have high face validity for a wide range of organizational settings. During optimism workshops, the first author asked all workshop participants (estimated at 2000+) whether the situations were likely to occur in their organizations. The 16 chosen items for the WES received the most positive reviews over most organizations. Among the 14 scenarios not chosen, many received ambivalent support. For example, the scenario 'You are told by a work colleague that you are being overconfident' was rated by professional sportspeople as highly likely to happen. In contrast, workshop participants from non-sport organizations strongly asserted that the scenario would not occur at their workplaces. Therefore, this was not included in the final selection of 16 items. The collection of scenarios is based on real life situations that were described in individual 
coaching consultations carried out by the lead author with members of diverse organizations.

Table 2. Hypothetical events in the WES

Situation Workplace event

You do some work that is highly praised.

A work colleague doesn't follow your instructions.

You are given a promotion.

You can't finish a project on time.

You are asked to be leader of a team.

You apply unsuccessfully for a position.

You achieve the best results of anyone in your team.

A co-worker criticises you.

A company/organization is keen for you to join them.

You are involved in a workplace accident.

Your strong commitment is recognised at a meeting.

You are late for a work appointment.

A co-worker asks you for some important advice.

You are feeling run-down at work.

You make a major contribution to the success of a project.

A superior in your organization ignores several suggestions you make.

There was also the question of how many scenarios to include. Peterson and Seligman (1984) suggested that one reason for the modest alpha coefficients in the ASQ is the small number of items, that is, only six positives and six negatives. Similarly, Proudfoot et al. (2001) argued that having 16 scenarios in the FSASQ led to better internal reliability than that found in the OASQ-a which has 10 scenarios. Therefore, we decided to include 16 situations in the WES.

Our present review showed there was a selection of 13 dimensions assessed by the 15 explanatory style questionnaires. The number in brackets indicates how many of the measures used the dimension: Internality (12), Stability (15), Globality (10), Controllability (3), Personal control (1), Colleague control (1), Externality (3), Intentionality (1), Consequences (1), Forseeability (1), Self-worth (1), Probability (1) and Chance (1). We chose to use the most popular dimensions of internality, stability and globality for two reasons. First, the theoretical support for the dimensions was the strongest and second, these three dimensions are incorporated in the most commonly used explanatory style questionnaire, the ASQ.

\section{Method}

\subsection{Participants and procedure}

A total of 341 participants ( $n=236$ women, $n=104$ men, $n=1$ unidentified sex) anonymously completed the WES and demographic details on a internet-based survey over the six month period that the contact website was kept open. In the study sample $60.6 \%$ were 
up to 40 years old, $32.9 \%$ occupied staff/supervisor positions and $45.1 \%$ worked in middle or top management. The majority of respondents had been in their present career for less than 20 years (69.3\%), had occupied their present career/management level for less than 11 years (71.3\%) and possessed university degrees (50.7\%).

Participants were reached by using the snowball sampling technique after the first author gave information sheets about the study to business chambers, women's network groups, community service clubs and human resource managers. The ethics clearance was given by the University's Ethics Committee.

\subsection{Measures}

Demographics. Participants provided information on six demographic variables: sex, age, number of years spent in present career, career level, number of years at present career level, education.

Workplace Explanations Survey. This 48-item questionnaire began with the following instructions:

The following 48 questions are about EXPLANATIONS for situations that might happen at work. For each question please IMAGINE the situation happening at your workplace. Think of the MOST LIKELY REASON for each situation. Think about a single reason. Then select the appropriate number for each question.

Each respondent then gave a rating from 1 to 7 on internality, stability and globality for each of the 16 hypothetical scenarios. This was achieved by having the same three questions and response scales following each scenario. Internality was assessed with the question: How much are you responsible for causing this situation? The Likert response scale was $1=$ Not due to me to $7=$ Totally due to me. Items labelled $a$ in Tables 3 and 4 are those assessing internality. Stability was assessed with the question: Will the cause again be present in the future? The response scale was $1=$ Never to $7=$ Always. Items labelled $b$ are those assessing stability. Globality was assessed with the question: Does this cause affect other parts of your life? The response scale was $1=$ Only this situation to $7=$ All areas of my life. Items labelled $c$ are those assessing globality.

\section{Results}

\subsection{Data Analysis}

All data analyses were conducted using SPSS Version 17.0. The following tests indicated the data were suitable for factor analysis: Bartlett's test of sphericity was significant, chi squared $(276)=2821, p<.001$ and the Kaiser-Meyer-Olkin measure of sampling adequacy was .88. We began with a factor analysis of the combined data for explanations of both the positive and negative scenarios. Analysis of this pool of responses using principal axis factoring and a promax rotation with Kaiser normalization revealed no meaningful factors.

Consequently, the data for negative situations and positive situations were analysed separately. Factor solutions of two, three and four were explored. The final factor solutions were the only ones that were conceptually meaningful and with satisfactory internal consistency. All of the items related to negative situations (that is, even-numbered a, b, c situations) loaded on the expected factors of Internality ( 8 items, $\alpha=.83$ ), Stability ( 8 items, 
$\alpha=.82$ ) and Globality ( 8 items, $\alpha=.87$ ). The loadings are shown on Table 3 .

Table 3. Factor loading for the 3-factor structure of the WES (Negative events)

\begin{tabular}{|c|c|c|c|}
\hline \multirow[b]{2}{*}{ Item No. } & \multicolumn{3}{|c|}{ Factor Loadings } \\
\hline & 1 & 2 & 3 \\
\hline \multicolumn{4}{|l|}{ Globality } \\
\hline $16 \mathrm{c}$ & .81 & & \\
\hline $8 c$ & .79 & & \\
\hline $2 c$ & .72 & & \\
\hline $4 c$ & .69 & & \\
\hline $6 c$ & .57 & & \\
\hline $10 \mathrm{c}$ & .57 & & \\
\hline $12 \mathrm{c}$ & .54 & & \\
\hline $14 \mathrm{c}$ & .44 & & \\
\hline \multicolumn{4}{|l|}{ Internality } \\
\hline $6 a$ & & .77 & \\
\hline $16 a$ & & .71 & \\
\hline $8 a$ & & .65 & \\
\hline $14 \mathrm{a}$ & & .64 & \\
\hline $12 \mathrm{a}$ & & .56 & \\
\hline $10 \mathrm{a}$ & & .54 & \\
\hline $2 a$ & & .49 & \\
\hline $4 a$ & & .48 & \\
\hline \multicolumn{4}{|l|}{ Stability } \\
\hline $16 \mathrm{~b}$ & & & .71 \\
\hline $8 b$ & & & .70 \\
\hline $14 b$ & & & .66 \\
\hline $12 b$ & & & .61 \\
\hline $4 b$ & & & .60 \\
\hline $10 \mathrm{~b}$ & & & .54 \\
\hline $2 b$ & & & .50 \\
\hline $6 \mathrm{~b}$ & & & .49 \\
\hline
\end{tabular}

Three factors were initially extracted from data for positive scenarios. One factor contained only the ratings for Scenario 13: “A co-worker asks you for some important advice." We explained this unexpected result by arguing the scenario could be interpreted as either positive, negative or neutral. Schulman and his colleagues (1989) list the conditions for an explanation to be suitable for explanatory style analysis. They state (p. 510): "The event must be unambiguously good or bad.” Therefore we deleted this question and repeated the analysis searching for two factors. The two factors extracted are clearly identified as Internality/Stability (14 items, $\alpha=.87$ ) and Globality ( 7 items, $\alpha=.84$ ). The factor loadings are presented in Table 4. 
Table 4. Factor loading for the 2-factor structure of the WES (Positive events)

\begin{tabular}{|c|c|c|}
\hline \multirow[b]{2}{*}{ Item No. } & \multicolumn{2}{|c|}{ Factor Loadings } \\
\hline & 1 & 2 \\
\hline \multicolumn{3}{|c|}{ Internality/Stability } \\
\hline 9a & .65 & \\
\hline $15 b$ & .64 & \\
\hline $5 b$ & .63 & \\
\hline $15 a$ & .63 & \\
\hline $11 \mathrm{a}$ & .61 & \\
\hline За & .61 & \\
\hline $5 a$ & .60 & \\
\hline $9 b$ & .58 & \\
\hline $11 \mathrm{~b}$ & .57 & \\
\hline $7 \mathrm{~b}$ & .56 & \\
\hline $1 \mathrm{a}$ & .54 & \\
\hline $7 a$ & .50 & \\
\hline $1 b$ & .49 & \\
\hline $3 b$ & .41 & \\
\hline \multicolumn{3}{|l|}{ Globality } \\
\hline $7 \mathrm{c}$ & & .86 \\
\hline $15 c$ & & .76 \\
\hline $5 c$ & & .67 \\
\hline $11 c$ & & .66 \\
\hline $1 c$ & & .59 \\
\hline 9c & & .54 \\
\hline $3 c$ & & .54 \\
\hline
\end{tabular}

Means, standard deviations, alpha coefficients and intercorrelations between the five factors can be seen in Table 5. As found in previous research, the present study showed there were significant intercorrelations between stability and globality for negative scenarios. However, there is an unexpected relationship between globality of negative situations with globality of positive situations $(r=.57, p<.01)$. This finding suggests a person who gives global (nonspecific) explanations for negative events will also do so when explaining positive events. This implies a person can be optimistic for problems and at the same time be pessimistic about personal workplace successes and achievements.

This unexpected contradiction led to us to search for more studies that show the interrelationships between all six explanatory style dimensions. We discovered this is rarely done. This is not unexpected as the analyses of explanatory style data most often rely on composite scores due poor internal consistency of individual dimensions. We found only three studies (Ashforth \& Fugate, 2006; Peterson et al. 1982; Peterson and Seligman 1984) with dimension interrelationships and each show similar unexpected positive relationships between globality for positive and negative situations $\left(r=.24^{*}, r=.24^{*}, r=.19^{* *}, r=\right.$ 
$\left..35^{* *}\right)$. Therefore, the relationship found in our study fits into the pattern reported by other research, except our correlation is stronger. No explanations were given in the other three papers. Taken together, the results show it may be inappropriate to carry out the common research practice of forming a total CPCN score by subtracting CoNeg from CoPos.

Table 5. Means, standard deviations, alpha reliabilities and intercorrelations

\begin{tabular}{lccccccc}
\hline \multicolumn{1}{c}{ Variable } & $\mathrm{M}$ & $\mathrm{SD}$ & 1 & 2 & 3 & 4 & 5 \\
\hline $\begin{array}{l}\text { Negative events } \\
1 \text { Internality }\end{array}$ & 4.24 & 0.98 & $(.83)$ & & & & \\
2 Stability & 4.09 & 0.92 & $.45^{* *}$ & $(.82)$ & & & \\
3 Globality & 3.93 & 1.20 & $.43^{* *}$ & $.46^{* *}$ & $(.87)$ & & \\
Positive Events & & & & & & & \\
4 Internality/Stability & 5.42 & 0.69 & .04 & $.12^{* *}$ & -.01 & $(.87)$ & \\
5 Globality & 4.76 & 1.13 & $.11^{*}$ & .01 & $.57^{* *}$ & $.37^{* *}$ & $(.84)$ \\
& & & & & & & \\
\hline
\end{tabular}

Notes. $N=341 .{ }^{*} p<.05 ;{ }^{* *} p<.01$. Coefficient alpha reliability estimates are listed on the diagonal in parentheses.

\section{Discussion}

Our review of the psychometric and theoretical properties of 15 explanatory style measures confirmed ongoing criticism, made over several decades, about a psychometric weakness found in most explanatory style questionnaires. Many instruments show low levels of internal consistency and satisfactory Cronbach alphas are only achieved by combining scores from the individual dimensions. It has been necessary to utilise these composite scores to achieve satisfactory criterion validity in studies of explanatory style and success in business. We regard this as a major weakness of research into the organizational benefits of having employees with optimistic explanatory styles. By relying on composite scores, it is impossible to identify the relative contributions of dimensions toward success. Moreover, it provides no clues as to which dimension(s) should be targeted in training sessions with individual staff and management.

The current review also identified the need for the development of an alternative measure of explanatory style, one which is specifically related to workplace events that can occur in any organization. There is a need for a work-related explanatory style tool to focus on a narrower domain of situations than that found in the ASQ which includes several situations most relevant to undergraduate students. However, it should avoid being too specific, such as the FSASQ which focuses on selling insurance. It is important for the measure to incorporate hypothetical scenarios that are truly found in a multitude of organizational structures. In the present study we describe the development of a new explanatory style questionnaire, the Workplace Explanations Survey (WES) which includes 16 scenarios that have been extensively trialled in many work sectors. 
We discovered several insights to guide the design of the WES. Whilst nearly all of the measures with satisfactory alpha coefficients for individual dimensions used negative events, there were contradictory theories and research findings about the respective value of negative and positive scenarios. Therefore, as this was an exploratory study, we included eight negative and eight positives situations. This number was chosen as lower numbers of events had been linked to poor internal consistency of many measures, for example, the ASQ with six negatives and six positives. It was hoped the 16 scenarios in the WES had high face validity and we suggest this played an important role in achieving good internal consistency for the five factors extracted by principal axis factoring. All Cronbach alphas exceeded .80 and only one scenario was rejected. This left 8 items each for internality, stability and globality for negative events plus 14 items for internality/stability and 7 items for globality for positive events. Factor analysis results of the WES strongly supported the argument that explanations for positive and negative situations are not two sides of a single coin. No meaningful factors were found when positive and negative events were analysed as a single group. Thus, our findings showed these explanations are on separate coins.

Our findings showed an unexpected correlation between globality of negative situations with globality of positive situations $(r=.57, \mathrm{p}<.01)$. As we have noted above, no other researchers have given explanations for this relationship when it has been reported in studies. We suggest this unexpected positive correlation exists because it could be easier to list global reasons (instead of specific reasons) for both positive and negative scenarios, as listing specific reasons possibly requires deeper analysis. Peterson (1991a) proposes a similar argument for preferring explanations of negative events over positive events. We strongly recommend further investigation is warranted to explain and also understand the consequences of this relationship. Importantly, this finding suggests that the common research practice of forming a total CPCN score by subtracting CoNeg from CoPos should be reviewed and reconsidered.

The merging of internality and stability into a single factor for positive explanations was also an unexpected result. We offer a possible explanation of this merging of dimensions. Several researchers have merged stability with globality (Cheng and Furnham 2003; Ciarrochi et al 2007; Seligman 1991) and others have eliminated the internality factor for both positive and negative events (Dykema et al 1996; Peterson and Chang 2003). Factor analysis of the WES shows that internality is a separate dimension for negative events, but not for positive events. We assert that future studies may find the negative dimensions of the WES could have higher criterion and construct validity than the WES positive dimensions as found in other explanatory style research (Peterson, 1991a).

Whilst the results on the development of the WES are encouraging, there are of course limitations which point to the need for further empirical studies. Because our research was exploratory, we were unable to carry out confirmatory factor analysis (CFA). Instead we identified the five factors of the WES with principal axis factoring which is a technique recommended for exploratory analysis (Allan \& Bennett, 2010; Field, 2005). To carry out CFA another sample of at least 300 participants is necessary (Tabachnick \& Fidell, 2007). Therefore, we are presently planning to collect data for CFA, as well as for validity studies. We are hopeful that other researchers will likewise undertake these important analyses. 
Clearly, lack of validity studies is another limitation of our exploratory study. Construct and criterion validity studies are required to examine theoretical commonalities. It is expected dimensions of the WES will show significant relationships to job related attitudes and behaviors such as occupational self-efficacy, work engagement, job satisfaction and career advancement. Importantly, future research needs to investigate test-retest reliability. There is an extra limitation to the study regarding demographics, that is, the 341 subjects were not asked to provide demographic information on the type of organization in which they worked. Thus, we have no indication of the range of organizations involved. However, this does not necessarily detract from our original aim to design a measure suitable for any organizational setting. Because we initially distributed the Research Information Sheet to a diverse range of sources across Australia, followed by the snowball technique spread over six months, we expected to achieve a wide range of subjects and organizations. Nevertheless, it is recommended that the WES be tested on subjects in a range of careers (e.g., finance and social work) to compare findings. Finally, in this study the response rate from men was much lower than women.

A major reason for this review and the development of the WES is linked to the deficiency of empirically assessed interventions which aim to boost levels of optimism. Measures of explanatory style with strong psychometric properties can play a much bigger role in interventions in organizations. There can be a synergistic relationship between optimism training and explanatory style measures. In combination, they promote each other. Organizations are more likely to undertake new training programs after measures accurately identify the staff/managers with pessimistic explanatory styles who would most benefit from training or coaching programs. The benefits of such testing and interventions such as training or personal coaching were shown by Proudfoot et al. (2009). They used the FSASQ to assess optimism levels of insurance sales agents before and after a 13-week training program. The training was based on a one-day course written by Seligman and his associates at Foresight Inc. Proudfoot and her colleagues found a significant increase in productivity, well-being and job satisfaction of employees at a large British insurance company. The training also led to a significant reduction in resignations (Proudfoot et al. 2009). Furnham and Sadka (1992) agree with Heaven (1994) and argue that a work-related explanatory style questionnaire would be a useful personnel selection tool. Such an instrument could be valuable in the recruitment of new staff as well as the advancement of existing personnel.

This review not only highlighted the need for an explanatory style measure to measure optimism/pessimism in any organization, but also the benefits to be gained by workplace interventions to boost optimism. We anticipate the WES will stimulate research into workplace optimism and provide clearer insights for optimism training, thus boosting both individual and organizational success.

\section{References}

Abramson, L.Y., Metalsky, G.I., \& Alloy, L.B. (1989). Hopelessness depression: A theorybased subtype of depression. Psychological Review, 96, 358-372.

Allen, P., \& Bennett, K. (2010). PASW statistics by SPSS: A practical guide, version 18.0. Melbourne: Cengage Learning Australia. 
Arntz, A., Gerlsma, C., \& Albersnagel, F.A. (1985). Attributional style questioned: Psychometric evaluation of the ASQ in Dutch adolescents. Advances in Behavioural Research and Therapy, 7, 55-89.

Ashforth, B.E., \& Fugate, M. (2006). Attributional style in work settings: Development of a measure. Journal of Leadership \& Organizational Studies, 12, 12-29.

Burns, M.O., \& Seligman, M.E.P. (1989). Explanatory style across life span: Evidence for stability over 52 years. Journal of Personality and Social Psychology, 56, 471-477.

Campbell, C.R. \& Martinko, M.J. (1998). An integrative attributional perspective of empowerment and learned helplessness: A multimethod field study. Journal of Management, 24, 173-200.

Carver, C.S. \& Scheier, M.F. (1991). Unresolved issues regarding the meaning and measurement of explanatory style. Psychological Inquiry, 2, 21-24.

Carver, C.S., Scheier, M.F., Miller, C.J., \& Fulford, D. (2009). Optimism. In C.R. Snyder \& S.J. Lopez (Eds.), Oxford handbook of positive psychology (2nd ed., pp. 303-312). New York: Oxford University Press.

Chang, E.C., \& Sanna, L.J. (2007). Affectivity and psychological adjustment across two adult generations: Does pessimistic explanatory style still matter? Personality and Individual Differences, 43, 1149-1159.

Cheng, H. \& Furnham, A, (2003). Attributional style and self-esteem as predictors of psychological well being. Counselling Psychology Quarterly, 16, 121-130.

Chiu, S-F., Peng, J-C., (2008). The relationship between psychological contract breach and employee deviance: The moderating role of hostile attributional style. Journal of Vocational Behavior, 73, 426-433.

Ciarrochi, J. \& Heaven, P.C.L. (2008). Learned social hopelessness: The role of explanatory role in predicting social support during adolescence. Journal of Child Psychology and Psychiatry, 49, 1279-1286.

Ciarrochi, J. \& Heaven, P.C.L. \& Davies, F. (2007).The impact of hope, self-esteem, and attributional style on adolescents' school grades and emotional well-being: A longitudinal study. Journal of Research in Personality, 41, 1161-1178.

Corr, P.J., \& Gray. J.A. (1995). Attributional style, socialization and cognitive ability as predictors of sales success: A predictive validity study. Personality and Individual Differences, 18, 241-252.

Corr, P.J., \& Gray. J.A. (1996a). Attributional style as a personality factor in insurance sales performance in the UK. Journal of Occupational and Organizational Psychology, 69, 83-87.

Corr, P.J., \& Gray. J.A. (1996b). Structure and validity of the Attributional Style 
Questionnaire: A cross-sample comparison. The Journal of Psychology, 130, 645-657.

Cutrona, C.E., Russel, D., \& Jones, R. (1995). Cross-situational consistency in causal explanations: Does attributional style exist? Journal of Personality and Social Psychology, 47, 1043-1058.

Douglas, S.C., \& Martinko, M.J. (2001). Exploring the role of individual differences in the prediction of workplace aggression. Journal of Applied Psychology, 86, 547-559.

Dykema, J., Bergbower, K., Doctora, J.D., \& Peterson, C. (1996). An attributional style questionnaire for general use. Journal of Psychoeducational Assessment, 14, 100-108.

Field, A. (2005). Discovering Statistics Using SPSS. London: Sage.

Furnham, A., Brewin, C.R., \& O'Kelly, H. (1994). Cognitive style and attitudes to work. Human Relations, 47, 1509-1521.

Furnham, A., Sadka, V., \& Brewin, C.R. (1992). The development of an occupational attributional style questionnaire. Journal of Organizational Behavior, 13, 27-39.

Gordon, R.A. (2008). Attributional style and athletic performance: Strategic optimism and defensive pessimism. Psychology of Sport and Exercise, 9, 336-350.

Haeffel, G.J., Gibb, B.E., Metalsky, G.I., Alloy, L.B., Abramson, L.Y., Hankin, B.L., Joiner, T.E., \& Swendsen, J.D. (2008). Measuring cognitive vulnerablility to depression: Development and validation of the Cognitive Style Questionnaire. Clinical Psychology Review, 28, 824-836.

Hanrahan, S.J., Grove, J.R., \& Hattie, J.A. (1989). Development of a questionnaire measure of sport-related attributional style. International Journal of Sport Psychology, 20, 114-134.

Heaven, P.C.L. (1994). Occupational attributional style and attitudes to work: An Australian study. Australian Psychologist, 29, 57-61.

Henry, P.C. (2005). Life stresses, explanatory style, hopelessness, and occupational class. International Journal of Stress Management, 12, 241-256. doi: 10.1037/1072-5245.12.3.241

Hewitt, A.K., Foxcroft, D.R., \& MacDonald, J. (2004). Multitrait-multimethod confirmatory factor analysis of the attributional style questionnaire. Personality and Individual Differences, 37, 1483-1491.

Higgins, N.C., \& Hay, J.L. (2003). Attributional style predicts causes of negative life events on the Attributional Style Questionnaire. The Journal of Social Psychology, 143, 253-271.

Jackson, B., Sellers, R.M., \& Peterson, C. (2002). Pessimistic explanatory style moderates the effect of stress on physical illness. Personality and Individual Differences, 32, 567-573.

Kent, R.L., \& Martinko, M.J. (1995). The development and evaluation of a scale to measure 
organizational atttributional style. In M.J. Martinko (Ed.), Attribution theory: An organizational perspective (pp. 53-75). Delray Beach, FL: St. Lucie Press.

Martinko, M.J., Douglas, S.C., \& Harvey, P. (2006). Attribution theory in industrial and organizational psychology: A review. International Review of Industrial and Organizational Psychology, 21, 127-187.

Martinko, M.J., Moss, S.E., Douglas, S.C., \& Borkowski, N. (2007). Anticipating the inevitable: When leader and member attribution styles clash. Organizational Behavior and Human Decision Processes, 104, 158-174.

Martin-Krumm, C.P., Sarrazin, P.G., \& Peterson, C. (2005). The moderating effects of explanatory style in physical education performance: A prospective study. Personality and Individual Differences, 38, 1645-1656.

Martin-Krumm, C.P., Sarrazin, P.G., Peterson, C., \& Famose, J.P. (2003). Explanatory style and resilience after sports failure. Personality and Individual Differences, 35, 1685-1695.

Norrish, J.M., \& Vella-Brodrick, D.A. (2009). Positive psychology and adolescents: Where are we now? Where to from here? Australian Psychologist, 44, 270-278. doi: $10.1080 / 00050060902914103$

Peterson, C. (1991a). The meaning and measurement of explanatory style. Psychological Inquiry, 2, 1-10.

Peterson, C. (1991b). Further thoughts on explanatory style. Psychological Inquiry, 2, 50-57.

Peterson, C. (1991c). On shortening the Expanded Attributional Style Questionnaire. Journal of Personality Assessment, 56, 179-183.

Peterson, C., \& Barrett, L.C. (1987). Explanatory style and academic performance among university freshmen. Journal of Personality and Social Psychology, 53, 603-607.

Peterson, C., \& Chang, E.C. (2003). Optimism and flourishing. In C.L.M. Keyes \& J. Haidt (Eds.), Flourishing: Positive psychology and the life well-lived (pp. 55-79). Washington, DC: American Psychological Association.

Peterson, C., Luborsky, L., \& Seligman, M.E.P. (1983). Depressive symptoms and unprompted causal attributions: Content analysis. Behavior Research and Therapy, 23, 96103.

Peterson, C., \& Seligman, M.E.P. (1984). Causal explanations as a risk factor for depression: Theory and evidence. Psychological Review, 91, 347-374.

Peterson, C., \& Seligman, M.E.P., \& Vaillant, G.E. (1988). Pessimistic explanatory style is a risk for physical illness: A thirty-five year longitudinal study. Journal of Personality and Social Psychology, 55, 23-27. 
Peterson, C., Semmel, A., von Baeyer, C., Abramson, L.Y., Metalsky, G.I., \& Seligman, M.E.P. (1982). The Attributional Style Questionnaire. Cognitive Therapy and Research, 6, 287-299.

Peterson, C., \& Steen, T.A. (2009). Optimistic explanatory style. In C.R. Snyder \& S.J. Lopez (Eds.), Oxford handbook of positive psychology (2nd ed., pp. 313-321). New York: Oxford University Press.

Peterson, C., \& Villanova, P. (1988). An Expanded Attributional Style Questionnaire. Journal of Abnormal Psychology, 97, 87-89.

Proudfoot, J.G., Corr, P.J., Guest, D.E., \& Dunn, G. (2009). Cognitive-behavioural training to change attributional style improves employee well-being, job satisfaction, productivity, and turnover. Personality and Individual Differences, 46, 147-153.

Proudfoot, J.G., Corr, P.J., Guest, D.E., \& Gray, J.A. (2001). The development and evaluation of a scale to measure occupational attributional style in the financial services sector. Personality and Individual Differences, 30, 259-270.

Proudfoot, J.G., Guest, D., Carson, J., Dunn, G., \& Gray, J. (1997). Effect of cognitivebehavioural training on job-finding among long-term employed people. The Lancet, 350, 96100 .

Sanjuan, P., \& Magallares, A. (2009). A longitudinal study of the negative explanatory style and attributions of uncontrollability as predictors of depressive symptoms. Personality and Individual Differences, 46, 714-718.

Schulman, P., Castellon, C., \& Seligman, M.E.P. (1989). Assessing explanatory style: The content analysis of verbatim explanations and the Attributional Style Questionnaire. Behaviour Research and Therapy, 27, 505-512.

Seligman, M.E.P. (1991). Learned optimism. New York: Knopf.

Seligman, M.E.P. (2006, February 15). Australian Financial Review Seminar. Sydney.

Seligman, M.E.P. (2011, April). Recovering from failure: Building resilience. Harvard Business Review, 89, 100-106.

Seligman, M.E.P., Nolen-Hoeksema, S., Thornton, N., \& Thornton, K.M. (1990). Explanatory style as a mechanism of disappointing athletic performance. Psychological Science, 1, 143-146.

Seligman, M.E.P., Peterson, C., Kaslow, N.J., Tanenbaum, R.L., Alloy, L.B., Abramson, L.Y. (1984). Attributional style and depressive symptoms among children. Journal of Abnormal Psychology, 93, 235-238.

Seligman, M.E.P., Reivich, K., Laycox, L., \& Gillham, J. (1995). The optimistic child. Sydney: Random House. 
Seligman, M.E.P., \& Schulman, P. (1986). Explanatory style as a predictor of productivity and quitting among life insurance sales agents. Journal of Personality and Social Psychology, 50, 832-838.

Sellers, R.M., \& Peterson, C. (1993). Explanatory style and coping with controllable events by student-athletes. Cognition and Emotion, 7, 431-441.

Tabachnick, B.G., \& Fidell, L.S. (2007). Using multivariate statistics (5th ed.). Boston: Pearson.

Tennen, H., \& Herzberger, S. (1985). Attributional Style Questionnaire. In D.J. Keyser \& R.C. Sweetland (Eds.), Test Critiques (Vol. 4, pp. 20-30). Kansas City: Test Corporation of America.

Thompson, M., Kaslow, N.J., Weiss, B., \& Nolen-Hoeksema, S. (1998). Children's Attributional Style Questionnaire: Psychometric properties. Psychological Assessment, 10, 166-170.

Welbourne, J.L., Eggerth, D., Hartley, T.A., Andrew, M.E., Sanchez, F. (2007). Coping strategies in the workplace: relationships with attributional style and job satisfaction. Journal of Vocational Behavior, 70, 312-325.

White, M. (2009, March). Why teach positive education in schools? Curriculum Leadership: An electronic journal for leaders in education. Retrieved from http://www.curriculum.edu.au/leader/why_teach_positive_education_in_schools.27066.html? issueID $=11751$

Whitley, B.E. (1991). A Short Form of the Expanded Attributional Style Questionnaire. Journal of Personality Assessment, 56, 365-369.

Xenikou, A. (2005). The interactive effect of positive and negative occupational attributional styles on job motivation. European Journal of Work and Organizational Psychology, 14, 4358.

Xenikou, A., Furnham, A., \& McCarrey, M. (1997). Attributional style for negative events: A proposition for a more reliable and valid measure of attributional style. British Journal of Psychology, 88, 53-69.

Zullow, H.M., Oettingen G., Peterson, C., \& Seligman, M.E.P. (1988). Pessimistic explanatory style in the historical record: CAVing LBJ, presidential candidates, and East versus West Berlin. American Psychologist, 43, 673-682. 